\title{
CLINCHRIVET AS AN ALTERNATIVE METHOD TO RESISTANCE SPOT WELDING
}

\author{
L'uboš KAŠČÁK*, Emil SPIŠÁK*, Jacek MUCHA* \\ * Faculty of Mechanical Engineering, Department of Technology and Materials, Technical University of Košice, Letná 9,04200 Košice, Slovakia \\ "Faculty of Mechanical Engineering and Aeronautics, Department of Mechanical Engineering, University address Politechnika Rzeszowska, \\ Al. Powstańców Warszawy 8, 35-959 Rzeszów, Poland
}

lubos.kascak@tuke.sk, emil.spisak@tuke.sk, i_mucha@prz.edu.pl

\begin{abstract}
Various materials are used in car body production which are not always possible to join by conventional joining methods such as resistance spot welding. Therefore ClinchRivet method seem to be possible alternative. The paper deals with evaluation of properties of the joints made by mechanical joining method - ClinchRivet. The joint is made with the using of a special rivet, which is pushed into the joined materials by the flat punch. Following materials were used for joining of this method: DX51D+Z and H220PD steel sheets. The tensile test for observing the carrying capacities and metallographicall analysis were used for the evaluation of joint properties. Some results of the tests of ClinchRivet joints were compared to the properties of the joints made by resistance spot welding.
\end{abstract}

Key words: Car Body Sheets, Spot Welding, Tensile Test, Microhardness

\section{INTRODUCTION}

The industry must meet the requirements for increased safety (product liability), the tightened regulations regarding environmental protection, as well as the requests of car drivers for more luxury features. Costly recall actions, ever increasing demands on the quality management, and the changing legal framework force the industry into an economic way of acting, especially with the harsh competitive conditions in the auto industry today (Barnes and Pashby, 2000; Buschke and Schappacher, 2006). One of the possibilities of decreasing the car weight and consequently lowering the fuel consumption is using various combinations of materials, such as combination of conventional deepdrawn steel sheet and high-strength steel sheet. Assembly and joining techniques must also be redesigned when adopting alternative materials (Mucha et al., 2011; Sun and Khaleel, 2005).

The increasing use of coated, lightweight and high-strength materials has led the automotive industry to re-examine traditional methods of component assembly. Direct welding of dissimilar sheet metals has proven to be difficult or impossible; thus, alternative joining techniques, such as mechanical fastening systems, have attracted increasing interest and applications. Mechanical fastening encompasses a broad range of methods, from threaded fasteners to different forms of rivets and mechanical interlocking methods (Mucha and Witkowski, 2013; Kaščák et al., 2010). Welding as the main joining technology in automotive industry offers unrivaled flexibility, but there are disadvantages such as processing time, fatigue weakness or thermal distortion. There are many joining technologies that are alternatives to resistance spot welding such as spot friction stir welding, adhesive bonding or new joining solutions including the plastic forming cold processes. The group of joints made of the native material with or without an additional fastener includes among the others the self-pierce riveting (SPR) joints, clinching joints and clinching joints with rivet. The main their disadvantage is lack of good double-side access for the joint forming tools. One of the alternative joining methods is the ClinchRivet process, which geometrically constrains two sheets by local deformation of the sheet metals using a punch and die, as well as the special rivet (Sevim, 2006; Szymczyk and Godzimirski, 2012).

The ClinchRivet is a cold process for joining two or more sheets by directly piercing the sheets with a special rivet. Since the ClinchRivet process does not require a pre-drilled hole unlike the conventional riveting, the joining speed is the same level with that of the spot resistance welding, and the equipment is similar (Abe, 2009; Johnson et al., 2009). The joint is formed by a rivet Fig. 1. The punch, under the pressure conveyed by a hydraulic power device, pushes the rivet to penetrate into the top plate, and the die shape causes the rivet to flare within the lower sheet in order to form a mechanical interlock. This process therefore requires access to both sides of the joint (Kaščák et al. 2012). It is similar to Clinching process, which is used without any additional elements. Joining the steel sheets of DX51D and H220PD grades by Clinching method was described in (Kaščák and Spišák, 2012).
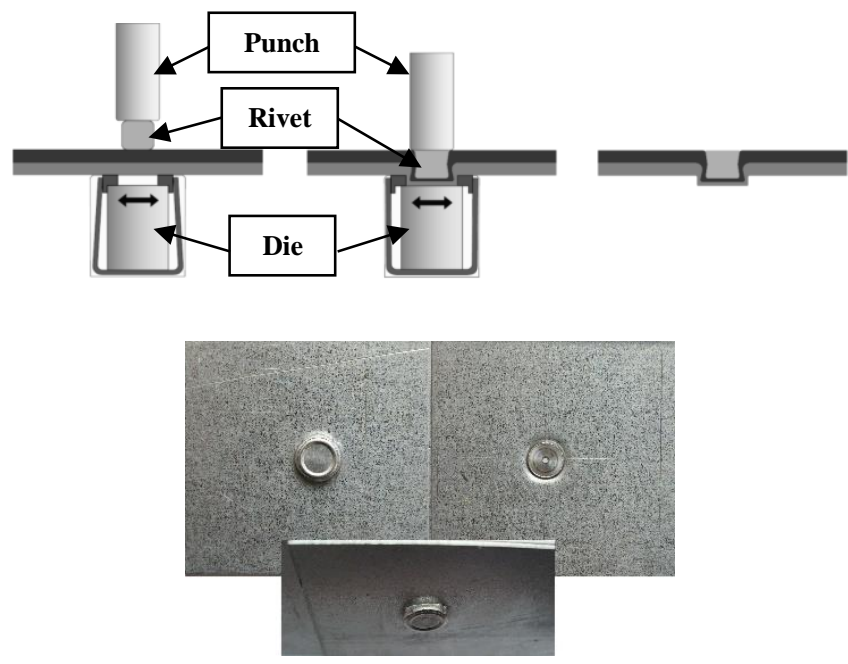

Fig. 1. Principle of ClinchRivet process 


\section{EXPERIMANTAL PROCEDURE}

The following steel sheets were used for experimets: microalloyed steel HSLA H220PD with the thickness of $0.8 \mathrm{~mm}$ and deep-drawing grade steel DX51D+Z with the thickness of $0.9 \mathrm{~mm}$. Basic mechanical properties and chemical composition of above mentioned materials are shown in Tab. 1 and Tab. 2. Mechanical properties of DX51D+Z steel were specified by producer.

Tab. 1. Basic mechanical properties of used steel sheets

\begin{tabular}{|c|c|c|c|c|}
\hline Material & $\begin{array}{c}\mathbf{R p}_{0.2} \\
{[\mathrm{MPa}]}\end{array}$ & $\mathbf{R}_{\mathbf{m}}[\mathrm{MPa}]$ & $\mathbf{A}_{80}[\%]$ & $\mathbf{n}_{90}$ \\
\hline H220PD & 238 & 382 & 36 & 0.228 \\
\hline $\mathrm{DX} 51 \mathrm{D}+\mathrm{Z}$ & 155 & $270-500$ & 23 & 0.24 \\
\hline
\end{tabular}

Tab. 2. Chemical composition (wt\%) of used steel sheets

\begin{tabular}{|c|c|c|c|c|c|c|}
\hline Material & $\mathbf{C}$ & $\mathbf{M n}$ & $\mathbf{S i}$ & $\mathbf{A l}$ & $\mathbf{C u}$ & $\mathbf{N i}$ \\
\hline H220PD & 0.012 & 0.435 & 0.119 & 0.041 & 0.040 & 0.013 \\
\hline DX51D+Z & 0.064 & 0.178 & 0.016 & 0.120 & 0.041 & 0.002 \\
\hline Material & $\mathbf{C r}$ & $\mathbf{T i}$ & $\mathbf{V}$ & $\mathbf{N b}$ & $\mathbf{M o}$ & $\mathbf{P}$ \\
\hline H220PD & 0.046 & 0.033 & 0.012 & 0.052 & 0.009 & 0.057 \\
\hline DX51D+Z & 0.023 & 0.002 & 0.005 & 0.015 & 0.004 & 0.016 \\
\hline
\end{tabular}

In order to evaluate the properties of the ClinchRivet joints and resistance spot welded joints, the following tests were performed: tension test and metallographical analysis. All the samples with dimensions of $40 \times 90 \mathrm{~mm}$ and $30 \mathrm{~mm}$ lapping according to STN 051122 standard were used for the experiments (Fig. 2). Six samples were prepared for both joining methods; one of them was left for metallographical analysis. It was not necessary to clean the sample surfaces before ClinchRivet joining. The ClinchRivet was carried out with the aluminium rivets (Fig. 3).

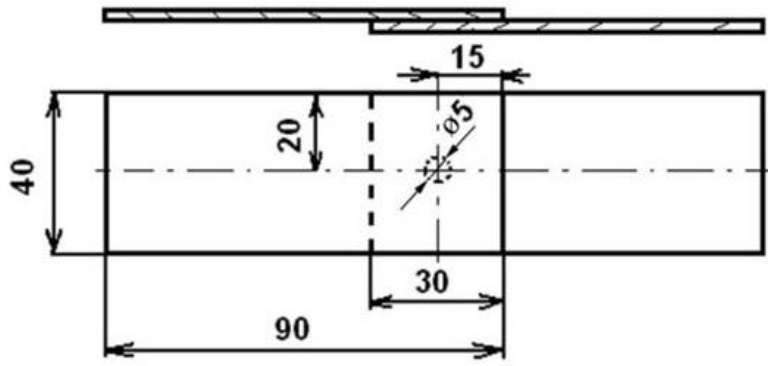

Fig. 2. Dimensions of the sample for tensile test
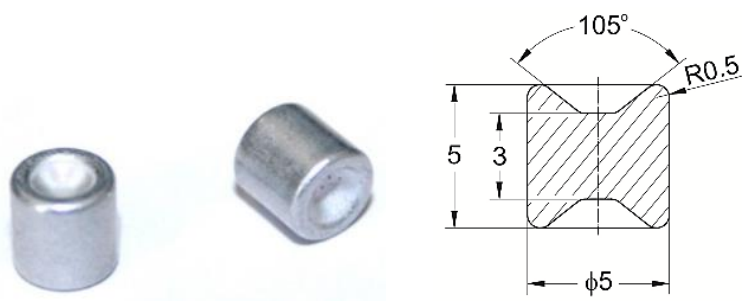

Fig. 3. Aluminium rivets for ClinchRivet method with dimensions

Resistance spot welding was carried out on a pneumatic spot welding-machine BPK 20 with the welding electrodes $\mathrm{CuCr}$ ac- cording to ON 423039.71 standard, where the diameter of $ø 5 \mathrm{~mm}$ of working area was used. The following parameters of resistance spot welding including pressing force of electrodes $\mathrm{Fz}$, welding time $T$ and welding current I were used:

$$
\begin{array}{ll}
\text { Samples with H220PD steels: } & \mathrm{Fz}=3.2 \mathrm{kN}, \\
& \mathrm{T}=12 \mathrm{cycles} \\
& \mathrm{I}=7.8 \mathrm{kA} \\
\text { Samples with DX51D+Z steels: } & \mathrm{Fz}=3 \mathrm{kN}, \\
& \mathrm{T}=12 \text { cycles } \\
& \mathrm{I}=7 \mathrm{kA}
\end{array}
$$

The parameters of resistance spot welding were determined according to the recommended welding parameters by IIW International Institute of Welding and adapted to welding machine BPK 20. The surfaces of the samples for resistance spot welding were degreased in concentrated $\mathrm{CH} 3 \mathrm{COCH} 3$.

The carrying capacities (Fmax) of the ClinchRivet joints as well as spot welded joints were measured according to standard STN 051122 - Welding: Tensile test on spot - and complete penetration welds. The test was carried out on the testing machine TIRAtest 2300 with the loading speed of $8 \mathrm{~mm} / \mathrm{min}$.

Further tests for quality evaluation of ClinchRivet joints and spot welded joints included the metallographical analysis. The quality of welded joints was evaluated by light microscopy on metallographical scratch patterns prepared according to ISO 6507-1 and ISO 6507-2 standards on Olympus TH 4-200 microscope.

\section{RESULTS AND DISCUSSION}

The measured values of carrying capacities of ClinchRivet (CR) joints and resistance spot welded (RSW) joints made by are shown in Tab. 3.

Tab. 3. Carrying capacities „Fmax” of CR joints and RSW joints

\begin{tabular}{|c|c|c|c|}
\hline \multicolumn{2}{|c|}{ H220PD } & \multicolumn{2}{c|}{ DX51D+Z } \\
\hline CR & RSW & CR & RSW \\
\hline 4952 & 5377 & 5020 & 7635 \\
\hline 4820 & 5487 & 4695 & 7840 \\
\hline 4703 & 5653 & 4667 & 7560 \\
\hline 4763 & 5492 & 4554 & 6947 \\
\hline 4725 & 5796 & 4911 & 7764 \\
\hline
\end{tabular}

Tensile tests were executed under displacement control conditions on the specimen configurations in order to characterise the static behaviour of the joints. The maximum shearing load was the most significant value that was obtained from the "shear forcedisplacement" curves - Fig.4 and Fig.5. The form of the curves indicates the behaviour of the joints under loading. The shearing load is higher for RSW joints than for CR joints in all observed combinations of joined materials.

All observed samples of RSW joints had higher values of carrying capacities in comparison to $\mathrm{CR}$ joints. The carrying capacity values of $C R$ joints were similar in cases of both tested materials. However, in case of RSW samples, there was a significant difference. The carrying capacity of DX51D+Z joints was approximately $2000 \mathrm{~N}$ higher than the carrying capacity of welds joining H220PD material. 


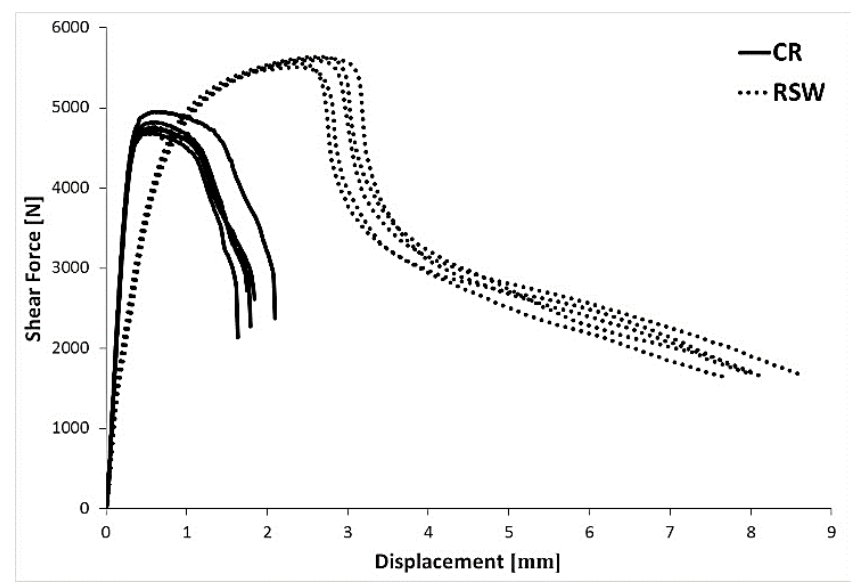

Fig. 4. Shear Force-displacement curves and deformation of the $C R$ and RSW joints after tensile test with H220PD materials

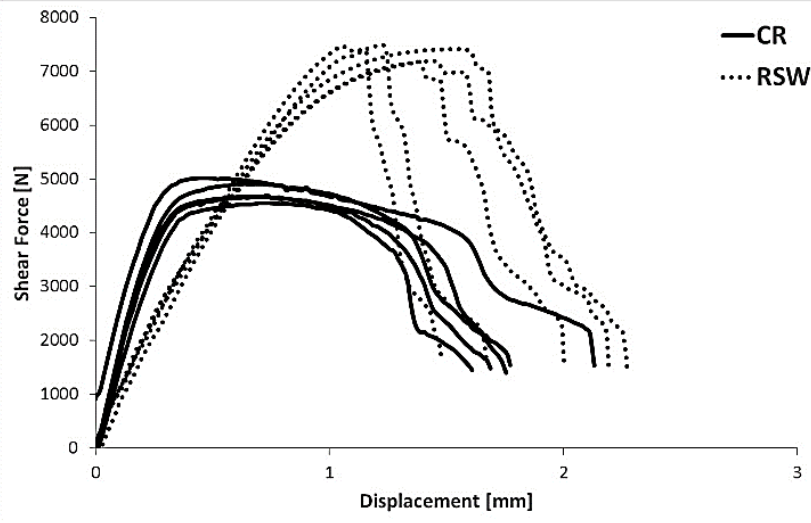

Fig. 5. Shear Force -displacement curves and deformation of the $C R$ and RSW joints after tensile test with DX51D+Z materials

The average maximum shearing load of ClinchRivet joint was: for samples with H220PD material around $4900 \mathrm{~N}$ with the displacement about $0.5 \mathrm{~mm}$ and for samples with DX51D materials around $5000 \mathrm{~N}$ with the displacement about $0.5 \mathrm{~mm}$. During the ClicnhRivet process the rivet and the riveted sheets undergo massive deformation to form the mechanical interlock. This energy is stored within the interlock leading to higher energy absorption. a)

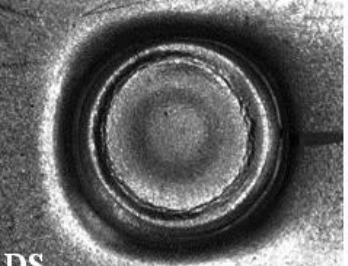

DS

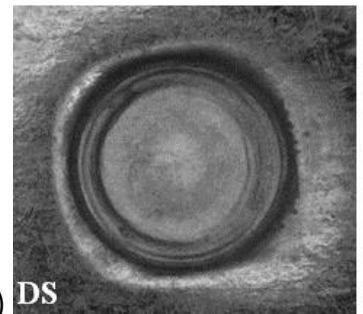

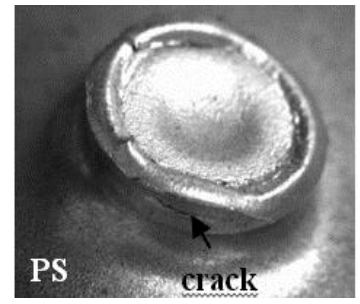

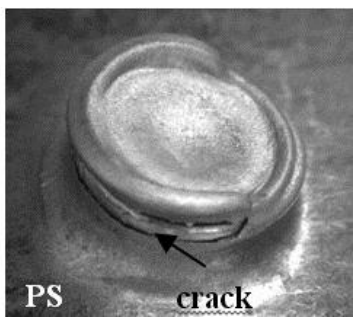

Fig. 6. ClinchRivet joints after tensile test: a) H220PD,
Joints made by ClinchRivet method failed in the manner of a press-stud in combination with the mode of one edge of the joint fails. This method results in a loosening of the joint after quite small displacements. The upper sheet was then pull out form the joint with the significant crack in the critical area - failed at the neck. There is insufficient material in the neck of the joint, and loading will result in failure in the neck; excessive elongation in the region of the joint neck causing cracks formation - Fig. 6 .

Metallographical analysis confirmed suitability of the ClinchRivet method for joining the observed materials. Using the rivet in this method led to significant hardening of the joint in the critical area (Fig. 7).
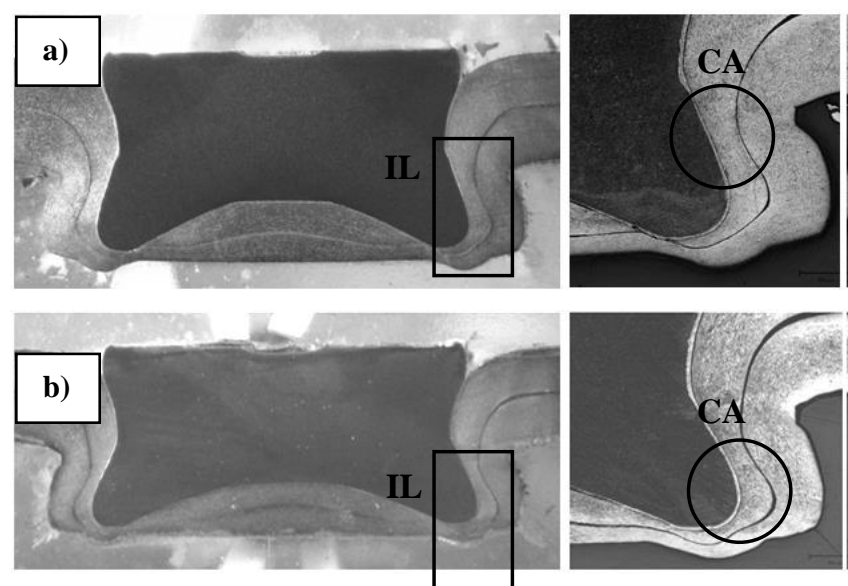

Fig. 7. ClinchRivet joints with interlocking and critical areas: a) H22OPD, b) DX51D+Z (IL - interlocking, CA - critical area)
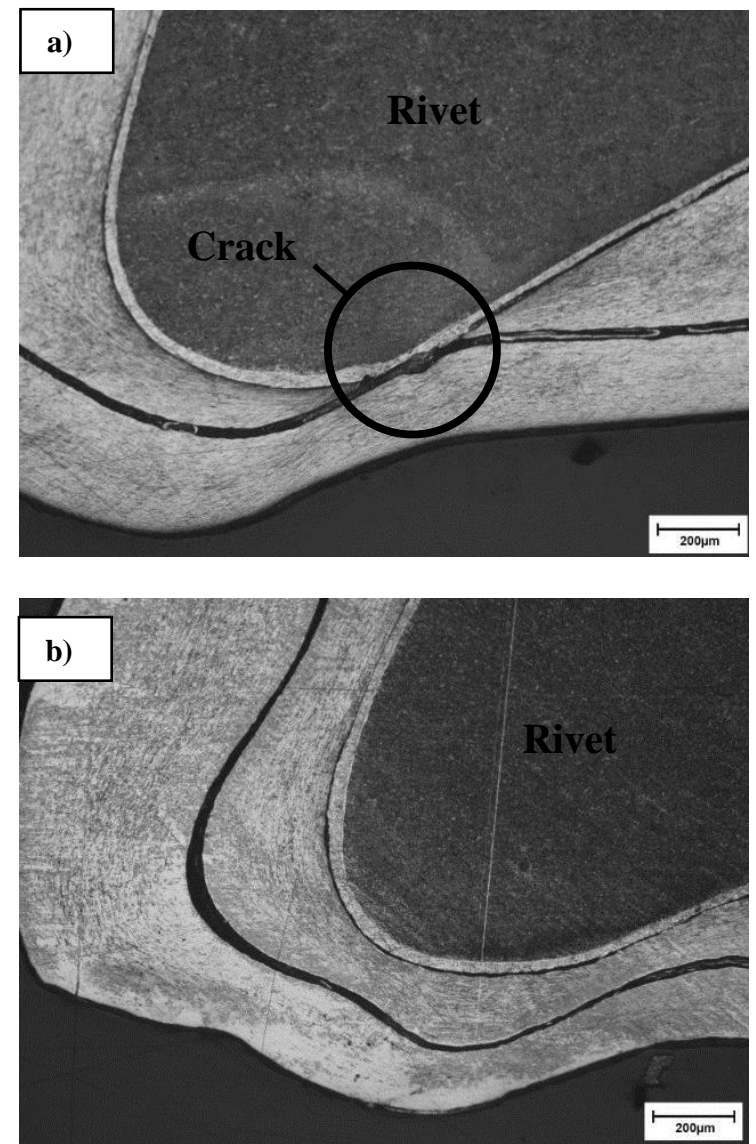

Fig. 8. Bottoms of the ClinchRivet joints: a) H220PD, b) DX51D+Z 
Fig. 8 shows the place of the transition from the bottom of the ClinchRivet joint into the bulge on the bottom's edges of both joined materials. The crack in this area was observed on the upper sheet (from the side of the punch) when H220PD steel sheets were joined - Fig. 8a. The rivet bears a major part of the load, therefore the crack created during the joining process does not have as significant influence on the carrying capacity of the joint as in the case of the clinching, where no rivets are used.
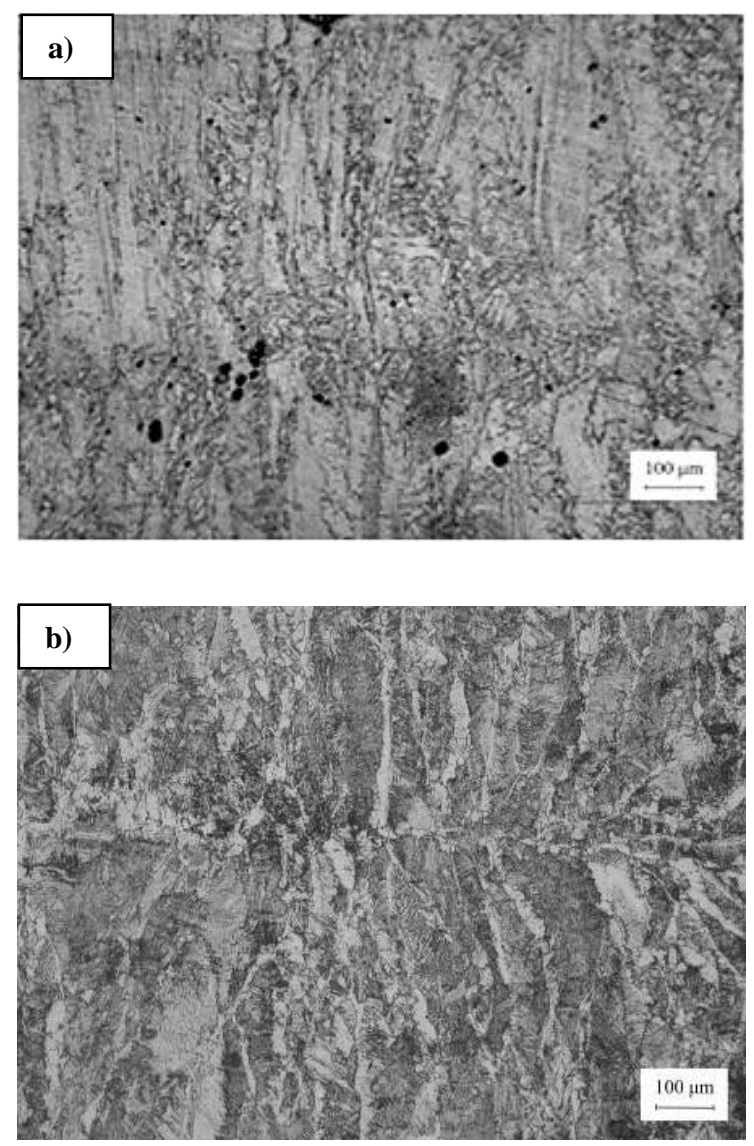

Fig. 9. Microstructures of welded materials in the area of weld nugget: a) H220PD, b) DX51D+Z

The metallographical analysis of resistance spot welded joints confirmed formation of fusion welded joints with characteristic areas of weld metal (WM), heat affected zone (HAZ) and base material (BM) - Fig. 9. The macrostructures show the solidification process of weld metal with a characteristic dendrite structure typical for resistance spot welds. No pores or cavities occurred in the weld metal of samples with DX51D materials. Some pores were observed in the area of weld nugget in the samples with H220PD materials as shown in Fig. 9a.

\section{CONCLUSIONS}

Although the high-speed mechanical fastening technique ClinchRivet is a young joining method, it has become more and more popular during the last decades. Most authors focus on the ClinchRivet process using steel rivets. The ClinchRivet using aluminium rivets is indeed a challenging task, since the strength of aluminium alloys are much weaker than that of steels. The aluminium rivet can be easily deformed when compressed into the plates, and hence no interlock is formed.

The ClinchRivet method using aluminium rivets is suitable for joining the tested materials. The carrying capacities of CR samples were sufficient and the metallographical analysis confirmed no occurrence of cracks or failures in the area of CR joints during joining process.

The main advantage of ClinchRivet technology is low running costs due to the fact that the processed components need not be heated. Only a die and a punch are used to press the sheet components to finish the whole joining process. The incomparable advantages of CR in practical production are as follows: no joining hot-stress has been produced, no poisonous gas has been given off, there is little noise in the process, the energy consumption is low, and this process leads to no damage to surface coating and does not require any premanufacturing of holes to the joined materials.

\section{REFERENCES}

1. Abe Y., Kato T., Mori. (2009), Self-piercing riveting of high tensile strength steel and aluminium alloy sheets using conventional rivet and die, Journal of Materials Processing Technology, Vol. 209, 3914-3922.

2. Barnes T.A., Pashby I.R. (2000), Joining techniques for aluminium spaceframes used in automobiles: Part II - adhesive bonding and mechanical fasteners, Journal of Material Processing Technology, Vol. 99, 72-79.

3. Buschke P., Schappacher W. (2006), Trends in the automotive industry steer new NDT applications, ECNDT-Fr.1.6.2, 1-12.

4. Johnson P., Cullen J.D., Sharples L., Shaw A., Al-Shamma'a A.I. (2009), Online visual measurement of self-pierce riveting systems to help determine the quality of the mechanical interlock, Measurement, Vol. 42, 661-667.

5. Kaščák L'., Spišák E. (2012), Clinching as a non-standard method for joining materials of dissimilar properties, Zeszyty Naukowe Politechniki Rzeszowskiej: Mechanika, Vol. 84, 31-41.

6. Kaščák L'., Spišák E., Mucha J. (2012), Evaluation of properties of joints made by clinching and self-piercing riveting methods, Acta Metallurgica Slovaca, Vol. 18, 172-180.

7. Kaščák L'., Spišák E., Mucha J. (2010), Joining of steel sheets for automotive industry using press joining method, Zeszyty Naukowe Politechniki Rzeszowskiej, No. 273, 121-126.

8. Mucha J., Spišák E., Kaščák L'. (2011), Non-standard car body element joining process with solid self-piercing rivet, The Archives of Automotive Engineering, Vol. 52, 57-67.

9. Mucha J., Witkowski, W. (2013), The experimental analysis of the double joint type change effect on the joint destruction process in uniaxial shearing test, Thin-Walled Structures, Vol. 66, 39-49.

10. Sevim I. (2006), Effect of hardness to fracture toughness for spot welded steel sheets, Material and Design, Vol. 27, 21-30.

11. Sun X., Khaleel M.A. (2005), Performance optimization of selfpiercing rivets through analytical rivet strength estimation, Journal of Manufacturing Processes, Vol. 7, 83-93.

12. Szymczyk E., Godzimirski, J. (2012), The influence of riveting process on sheets fatigue life - the stress state analysis, Acta Mechanica et Automatica, Vol. 6, 74-81.

Acknowledgment: Authors are grateful for the support of experimental works by project VEGA No.1/0396/11: "Research and optimization of evaluation methods of strength and plastic properties of thin tinplates". 